\title{
Neutrophilic eccrine hidradenitis in a patient with FOLFOX chemotherapy
}

\author{
Ana Cristina da Silva Sousa ${ }^{\circledR}$, Rita Venina Amaral Pereira Guedes ${ }^{1}$, Nuno Miguel Bouças Vasconcelos Noronha
} Menezes $^{1}$, Antónia Maria Cruz Furtado², Armando Manuel Baptista ${ }^{1}$

\begin{abstract}
This case study describes a 37-year-old Caucasian male with pruritic papules and plaques-some with central erosion-on the arms, neck, and trunk that appeared after chemotherapy with FOLFOX (folinic acid, fluorouacil, and oxiliplatin) for colon cancer. A histological examination showed features of neutrophilic eccrine hidradenitis. To the best of our knowledge, this is the first reported case of neutrophilic eccrine hidradenitis due to FOLFOX.
\end{abstract}

Keywords: neutrophilic eccrine hidradenitis, colon cancer, FOLFOX

Received: 22 January 2018 | Returned for modification: 16 March 2018 | Accepted: 7 May 2018

\section{Introduction}

Neutrophilic eccrine hidradenitis (NEH) is an uncommon, benign disease that was described for the first time in 1982 by Harrist et al. (1). The pathogenesis remains unknown and the diagnosis is confirmed histologically. NEH presents as a neutrophilic infiltration, with or without necrosis, around and in the ducts and coils of eccrine sweat glands. The cutaneous lesions are typically pruritic, painful, erythematous-violaceous papules or plaques on the limbs, trunk, neck, and face (2).

NEH has been associated with chemotherapy for hematologiconcologic diseases and with hematologic neoplasia per se (3-5). Infrequently, it is correlated with solid tumors such as Wilms' tumor, osteosarcoma, testicular cancer, and breast cancer as a paraneoplastic condition (6).

Sometimes the distinction between NEH and Sweet's syndrome or between NEH and facial cellulitis can be challenging $(7,8)$. The correct diagnosis is crucial and prevents the misuse of antibiotics.

\section{Case report}

A 37-year-old Caucasian male patient diagnosed with colon adenocarcinoma was referred to our department due to generalized cutaneous lesions after the second cycle of adjuvant chemotherapy (FOLFOX). Other than the chemotherapy medications, the patient denied ingesting any drugs. The lesions were itchy and non-painful. They began 3 days after the second chemotherapy cycle and had an acute generalized progression.

The physical examination revealed well-delimited, non-scaly, erythematous-violaceous papules and plaques, some with central erosion. They were mainly located on the arms, neck, trunk, and back; the scalp, mucosa, and genitalia were spared (Figs. 1 and 2).

A punch biopsy was made in a papule located on the trunk. Histological features revealed an inflammatory neutrophilic infiltrate surrounding the eccrine glands, with associated necrosis. Leukocytoclastic vasculitis was not seen and the PAS staining was negative. These findings favored a diagnosis of NEH (Fig. 3).

Potent topical corticosteroids were given and the lesions began to disappear after 2 weeks of treatment (Fig. 4). NEH recurred with less intensity after the third cycle of chemotherapy. After a multidisciplinary consult with the oncology team, the patient chose to continue treatment with FOLFOX and to use topical corticosteroids if the lesions reappeared. During the subsequent cycles of chemotherapy and through 2 years of follow up the lesions did not recur.

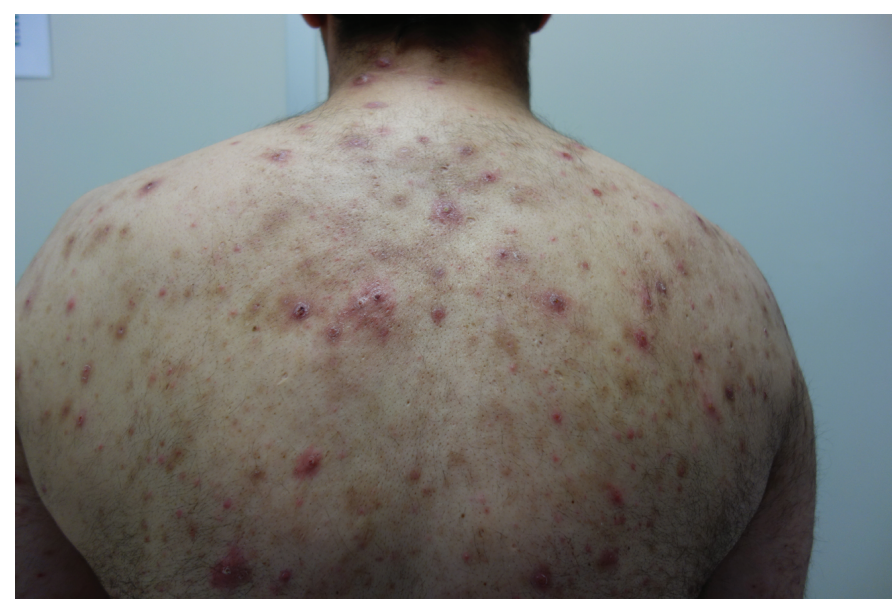

Figure 1 | Well-delimited, violaceous papules with central erosion on the back.

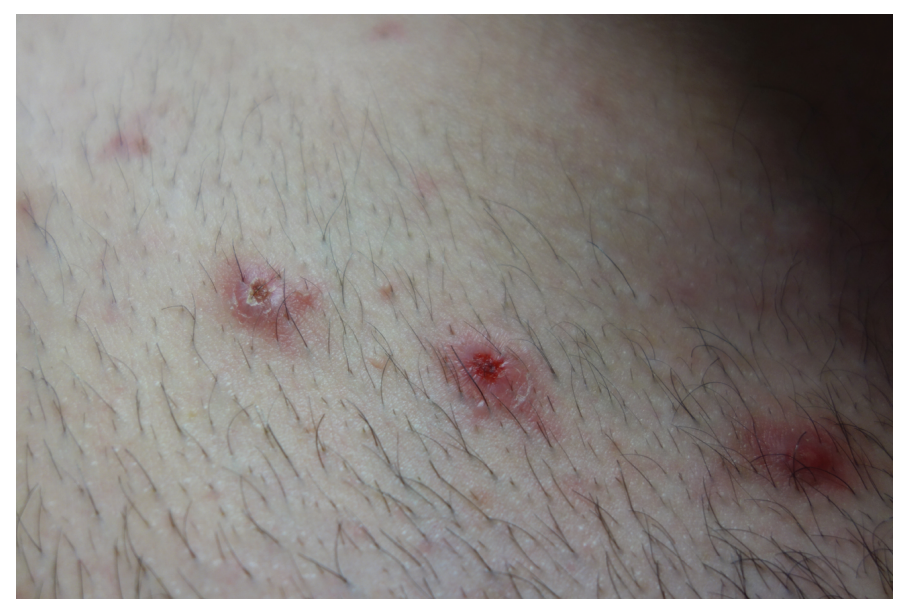

Figure 2 | Papules with central erosion. 


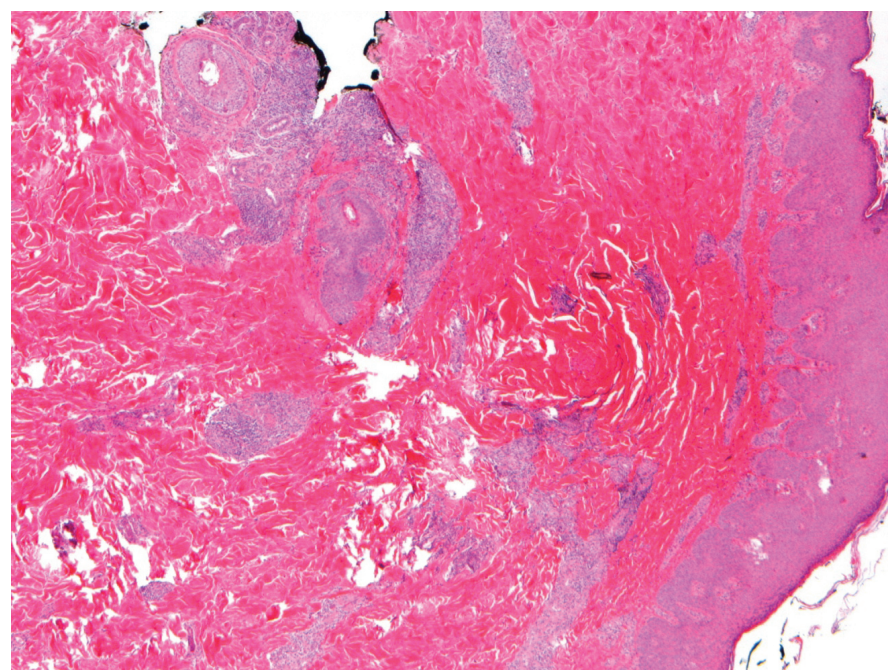

Figure 3 | Acantosis, polymorphonuclear neutrophils around sweat glands in the dermis, with consequent destruction.

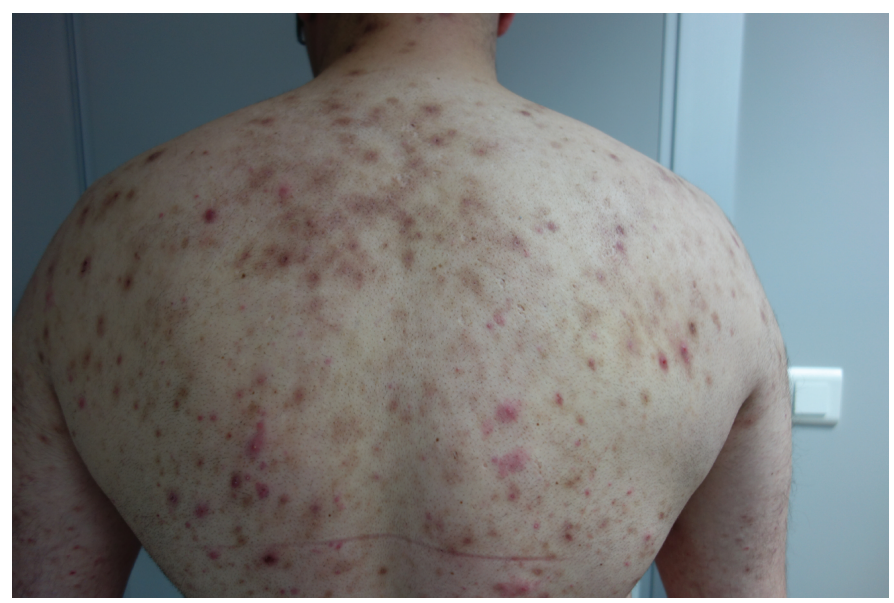

Figure 4 | Partial resolution of the lesions after 1 week of treatment.

\section{Discussion}

$\mathrm{NEH}$ is an uncommon disease described as an infiltration of neutrophils in and around the eccrine gland. It is observed mainly in patients undergoing chemotherapy for hematologic-oncologic diseases (1-6). There are several hypotheses that try to explain the pathophysiology, but it remains uncertain. One of the theories posits that a direct cytotoxic effect of the drug through the eccrine gland is the cause (2). Another hypothesis is that NEH is a neutrophilic dermatitis and that these entities can be seen as paraneoplastic conditions (3-6).

Some cases reports describe an association between NEH and infection, whereas others have found NEH in healthy people (618). There is one case report describing a patient with NEH that was caused by acetaminophen (19).

There are numerous cytotoxic chemotherapy agents associated with NEH, including bleomycin, chlorambucil, cyclophosphamide, cytarabine, doxorubicin, lomustine, mitoxantrone, topotecan, vincristine, cetuximab, carbamazepine, and azathioprine $(20-24)$.

FOLFOX therapy is a combination of folinic acid, fluorouracil, and oxaliplatin that is used as adjuvant chemotherapy in colon cancer. The medications act synergistically to suppress the DNA and RNA synthesis leading to cell death.

Fluorouracil can exert a cytotoxic effect through the erroneous synthesis of DNA and the inhibition of thymidylate synthase. Most of the fluorouracil is metabolized in the liver, where dihydropyrimidine dehydrogenase is primarily expressed. Folinic acid acts as a synergistic agent, helping fluorouracil to inhibit thymidylate synthase. Oxaliplatin is a platinum-based complex that binds preferentially to guanine and cytosine nucleotides, leading to the cross-linking of DNA and thus blocking DNA replication and transcription. The main route of oxaliplatin elimination is renal excretion. Oxaliplatin and fluorouracil interact with one another, making it difficult to assess their pharmacokinetics because of the platinum complexes. The main dermatologic side effects of FOLFOX therapy are pruritus, nail discoloration, onycholysis, alopecia, and hand-foot syndrome (25).

To the best of our knowledge, this is the first reported case of NEH triggered by FOLFOX chemotherapy. The probable mechanism is the direct cytotoxic effect on the eccrine glands of folinic acid, fluorouracil, and oxaliplatin, but more observations are needed to confirm this hypothesis.

$\mathrm{NEH}$ is a benign condition that resolves after 3 to 4 weeks. Treatment serves only to relieve symptoms, and so the use of topical corticosteroids, cold compresses, and rest is recommended (1-4). Successful treatment with colchicine was reported in two cases $(26,27)$. As a way to prevent possible recurrences, some authors suggest the use of oral dapsone (28).

\section{Conclusion}

We present a case of NEH in a patient undergoing FOLFOX therapy. Despite having many chemotherapeutic drugs in its etiology, this is the first case of NEH associated with FOLFOX. The probable cause is a direct cytotoxic effect of the combined drugs on the sweat glands. More observations are needed to evaluate these cytotoxic effects and the pathophysiology of this rare disease.

\section{References}

1. Harrist TJ, Fine JD, Berman RS, Murphy GF, Mihm MC Jr. Neutrophilic eccrine hidradenitis. A distinctive type of neutrophilic dermatosis associated with myelogenous leukemia and chemotherapy. Arch Dermatol. 1982;118:263-6.

2. Bachmeyer C, Aractingi S. Neutrophilic eccrine hidradenitis. Clin Dermatol. 2000;18:319-30.

3. Pierson JC, Helm TN, Taylor JS, Elston DM, Tuthill RJ. Neutrophilic eccrine hidradenitis heralding the onset of acute myelogenous leukemia. Arch Dermatol. 1993;129:791-2.

4. Gomez Vazquez M, Peteiro C, Toribio J. Neutrophilic eccrine hidradenitis heralding the onset of chronic myelogenous leukaemia. J Eur Acad Dermatol Venereol. 2003;17:328-30.

5. Saada V, Aractingi S, Leblond V, Marinho E, Frances C, Chosidow O. Neutrophilic eccrine hidradenitis associated with relapse of acute myeloblastic leukemia. Ann Dermatol Venereol. 1998;125:420-2.

6. Cohen PR. Neutrophilic dermatoses occurring in oncology patients. Int J Dermatol. 2007;46:106-11.

7. Bardenstein DS, Haluschak J, Gerson S, Zaim MT. Neutrophilic eccrine hidradenitis simulating orbital cellulitis. Arch Ophthalmol. 1994;112:1460-3.

8. Srivastava M, Scharf S, Meehan SA, Polsky D. Neutrophilic eccrine hidradenitis masquerading as facial cellulitis. J Am Acad Dermatol. 2007;56:693-6.

9. Morice A, Penven K, Comoz F, Cribier B, Dompmartin A, Leroy D. Neutrophilic eccrine hidradenitis in a healthy patient. Ann Dermatol Venereol. 2005;132:686-8. 
10. Andreu-Barasoain M, Calzado L, Salamanca J, Nuño A, Gamo R, Gomez de la Fuente E, et al. Generalized idiopathic neutrophilic eccrine hidradenitis in a 7-month-old child. J Am Acad Dermatol. 2012;67:e133-4.

11. Lee WJ, Kim CH, Chang SE, Lee MW, Choi JH, Moon KC, et al. Generalized idiopathic neutrophilic eccrine hidradenitis in childhood. Int J Dermatol. 2010;49:75-8.

12. Rouanet I, Jantac M, Lechiche C, Hope-Rapp E, Sotto A. Neutrophilic eccrine hidradenitis in an HIV-1-infected patient. AIDS. 2012;26:775-6.

13. Bachmeyer C, Reygagne P, Aractingi S. Recurrent neutrophilic eccrine hidradenitis in an HIV-1-infected patient. Dermatology. 2000;200:328-30.

14. Krischer J, Rutschmann 0 , Roten SV, Harms $M$, Saurat JH, Pechère M. Neutrophil eccrine hidradenitis in a patient with AIDS. J Dermatol. 1998;25:199-200.

15. Oono T, Matsuura H, Morizane S, Yamasaki O, Iwatsuki K. A case of infectious eccrine hidradenitis. J Dermatol. 2006;33:142-5.

16. Takai T, Matsunaga A. A case of neutrophilic eccrine hidradenitis associated with streptococcal infectious endocarditis. Dermatology. 2006;212:203-5.

17. Combemale P, Faisant M, Azoulay-Petit C, Dupin M, Kanitakis J. Neutrophilic eccrine hidradenitis secondary to infection with Serratia marcescens. Br J Dermatol. 2000;142:784-8.

18. Antonovich D, Berke A, Grant-Kels JM, Fung M. Infectious eccrine hidradenitis caused by Nocardia. J Am Acad Dermatol. 2004;50:315-8.

19. EL Sayed F, Ammoury A, Chababi M, Dhaybi R, Bazex J. Neutrophilic eccrine hidradenitis to acetaminophen. J Eur Acad Dermatol Venereol. 2006;20:1338-40.
20. Lienesch DW, Mutasim DF, Singh RR. Neutrophilic eccrine hidradenitis mimicking cutaneous vasculitis in a lupus patient: a complication of cyclophosphamide. Lupus. 2003;12:707-9.

21. Bhanu P, Santosh KV, Gondi S, Manjunath KG, Rajendaran SC, Raj N. Neutrophilic eccrine hidradenitis: a new culprit-carbamazepine. Indian J Pharmacol. 2013;45:91-2.

22. Turan H, Kaya E, Gurlevik Z, Erdem H, Oktay M. Neutrophilic eccrine hidradenitis induced by cetuximab. Cutan Ocul Toxicol. 2012;31:148-50.

23. Schmutz JL. Neutrophilic eccrine hidradenitis and azathioprine hypersensitivity syndrome. Ann Dermatol Venereol. 2014;141:738-9.

24. Grillo E, Vano-Galvan S, Gonzalez C, Pedro J. Letter: Neutrophilic eccrine hidroadenitis with atypical findings. Dermatol Online J. 2011;17:14

25. Bano N, Najam R, Mateen A. Comparative assessment of skin and subcutaneous toxicity in patients of advanced colorectal carcinoma treated with different schedules of FOLFOX. Asian Pac J Cancer Prev. 2013;14:1781-6.

26. Belot V, Perrinaud A, Corven C, de Muret A, Lorette G, Machet L. Adult idiopathic neutrophilic eccrine hidradenitis treated with colchicine. Presse Med. 2006;35:1475-8.

27. Scheer HS, Kamarashev J, Weibel L. Successful treatment of recurrent idiopathic plantar eccrine hidradenitis with colchicine. Arch Dermatol. 2012;148:1357-9.

28. Shear NH, Knowles SR, Shapiro L, Poldre P. Dapsone in prevention of recurrent neutrophilic eccrine hidradenitis. J Am Acad Dermatol. 1996;35:819-22. 